\title{
Reflexão crítica sobre as escolas bilíngues (português/inglês) de imersão e internacionais na cidade de São Paulo
}

\section{Analytical reflection on bilingual immersion schools (Portuguese / English) and international schools in the city of São Paulo}

Aline Nunes Möller é graduada em Pedagogia pelo Instituto Vera Cruz. Trabalha desde 2013 em escolas bilíngues de imersão e internacionais.

\section{Contato: alinenmoller@gmail.com}

Maria Paula Zurawski é doutoranda e mestre em Educação pela FEUSP e graduada em Artes Cênicas pela ECA-USP. É formadora em projetos de capacitação em redes públicas e particulares, além de atriz do Grupo Furunfunfum de teatro para crianças. Professora dos cursos de Licenciatura em Pedagogia e de pósgraduação em Gestão Pedagógica e Formação em Educação Infantil no Instituto Vera Cruz.

Contato: mariapaulazu@gmail.com

\section{Resumo}

A educação bilíngue é um assunto atual, que vem ganhando cada vez mais espaço na educação brasileira. 0 objetivo deste artigo é refletir sobre as escolas bilíngues (português/ inglês) de imersão e internacionais, na cidade de São Paulo, por meio de tópicos muito explorados e relacionados a essa temática, tais como: o crescimento do número de escolas bilíngues, a definição de uma escola bilíngue, a legislação atual do Brasil em relação à regulamentação dessa modalidade de escola e o que é ser bilíngue, além de ponderar sobre a formação adequada de profissionais e a supervisão sistemática e periódica dos estabelecimentos de ensino. 0 resultado dessa pesquisa teórica permanece em aberto, principalmente em razão da falta de um padrão das 
escolas bilíngues, por carência de embasamento teórico, e, também, por causa do sigilo exigido pelas escolas em relação à metodologia.

Palavras-chave: Bilinguismo. Educação bilíngue. Escola internacional. Escola de imersão.

\begin{abstract}
Bilingual education is a current subject, which has been increasingly gaining space in Brazilian education. The goal of this article is to reflect on bilingual immersion schools (Portuguese / English) and international schools in the city of São Paulo, through highly explored topics related to this subject, such as: the growth of the number of bilingual schools, the definition of a bilingual school, the current Brazilian legislation regarding the regulation of this kind of school, and what it is to be a bilingual person. In addition, the text refers to the appropriate professional training and the periodic and systematic supervision of immersion and international schools. After all, bilingualism is an educational necessity of contemporaneity and needs to be deepened. The result of this theoretical research remains open, mainly due to the lack of a standard of bilingual schools and a lack oftheoretical background, and also because of the secrecy required by the schools in relation to the methodology. Key words: Bilingualism. Bilingual education. International school. Immersion school.
\end{abstract}

\title{
Introdução
}

A educação bilíngue vem crescendo e ganhando espaço no Brasil. Atualmente há uma grande procura por essas escolas. 0 aprendizado de uma segunda língua é considerado cada vez mais importante na sociedade globalizada na qual vivemos, principalmente o do idioma inglês, porque, segundo Crystal (2002), apesar de o mandarim ser a língua mais falada do mundo, o inglês é considerado a língua mundial, já que é a segunda língua dominada pela maioria das pessoas do planeta. Além de ser uma combinação de outros idiomas (BOWERN, 2015), tais como o francês e $o$ alemão, $o$ inglês utiliza $o$ alfabeto mais comum entre as línguas, principalmente as ocidentais, o que a torna a língua com maior influência política, econômica, acadêmica etc. 
Ao mesmo tempo, muitas especulações são geradas em torno da temática do bilinguismo. Seria a escola bilíngue a nova "escola do momento", e, assim que passar a "moda", ela se tornará ultrapassada? Também é possível especular sobre o estudo acadêmico diferenciado, os modelos internacionais e como essa educação será reconhecida, no Brasil e no mundo, quando a criança concluir o Ensino Médio e for para a faculdade.

Enfim, muitas questões são levantadas em relação à imersão na segunda língua e seus benefícios para a criança. Em meio a tantas perguntas, o tema foi escolhido para buscar entender melhor o universo bilíngue e esclarecer parte dessas dúvidas.

As questões que a pesquisa procura responder são: Por que o número de escolas bilíngues está crescendo tanto? 0 que define uma escola bilíngue? Existe uma legislação no Brasil que regulamente a escola bilíngue? Qual a diferença entre escola de imersão e escola internacional? 0 que torna uma criança bilíngue?

Para responder a essas questões, foram realizadas uma pesquisa bibliográfica, duas entrevistas ${ }^{1}$ com gestores de duas escolas de Educação Infantil bilíngue (inglês/português) das zonas oeste e sul de São Paulo, sendo uma delas de imersão e a outra internacional; e uma análise dos dados coletados nas entrevistas, que utilizou como fundamentação teórica a pesquisa bibliográfica elaborada anteriormente. 0 foco da análise é a diferenciação entre as escolas bilíngues de imersão e as internacionais.

0 bilinguismo é uma necessidade educativa da contemporaneidade e precisa ser aprofundado. Segundo reportagem do jornal O Estado de S.Paulo ${ }^{2}$, aproximadamente $80 \%$ das escolas bilíngues brasileiras estão localizadas apenas no estado de São Paulo. Porém, pouco se sabe sobre as diferenças entre as escolas bilíngues de imersão e as escolas bilíngues internacionais, principalmente por causa do sigilo exigido pelas escolas em relação às suas metodologias. Portanto, escolhendo a capital do estado de São Paulo para o desenvolvimento da pesquisa, o objetivo deste estudo é compreender as principais diferenças entre a escola de Educação Infantil bilíngue de imersão e a escola de Educação Infantil bilíngue internacional no contexto brasileiro, particularmente na cidade de São Paulo, nos idiomas português e inglês. Abre-se espaço, também, para uma extensa reflexão sobre tópicos como a falta de um padrão das escolas bilíngues, a carência de embasamento teórico e o sigilo, tanto na escola de imersão bilíngue quanto na escola internacional.
1. As entrevistas não foram incluídas neste artigo, devido ao número reduzido de páginas disponibilizadas.

2. ESTADO, Agência. Cresce procura por escolas bilíngues no País. Jornal O Estado de S.Paulo. Disponível em: goo.gl/PTgAM6. Acesso em 20.06.2017. 
Este estudo é relevante porque aborda um assunto atual, ainda pouco explorado, estudado e divulgado no meio acadêmico, e que vem ganhando cada vez mais espaço na educação brasileira.

\section{0 crescimento das escolas bilíngues}

As primeiras escolas bilíngues surgiram na Europa, mais precisamente na Irlanda e no País de Gales, em 1921. Porém, a educação bilíngue existe há mais de 5 mil anos, segundo Mackey (1978).

De acordo com E.G. Lewis (1977), a educação bilíngue existe há muito mais que um século. Ao longo da história, se pensarmos nas sociedades remotas e seus contextos sociais, as diferenças comunicacionais criadas pelo encontro de povos de línguas diferentes causavam uma necessidade de comunicação que precisava ser resolvida. Esse contexto gerava uma educação bilíngue ou multilíngue, mesmo que de maneira informal. Como não falavam o mesmo idioma, as pessoas utilizavam outras formas de comunicação para expressar o que queriam, como os gestos. Aos poucos, acredita-se que elas aprendessem palavras de outros idiomas e que isso facilitasse o diálogo, além de possivelmente originar novos idiomas.

Atualmente, podemos encontrar o bilinguismo em contextos sociais muito diversificados, como nos Estados Unidos, na Inglaterra, no Canadá e no Brasil. Nos Estados Unidos e na Inglaterra os estudos sobre bilinguismo estão voltados para as minorias étnicas desses países, como o caso dos mexicanos que vão para aquele país em busca de melhores condições de vida e oportunidades. Nesse contexto, a língua materna passa a ser a língua menos utilizada, normalmente praticada em casa e em contextos mais familiares, e os mexicanos passam a falar mais inglês do que espanhol. Isso normalmente acontece em casos de imigração ou de ex-colônias, porque o bilinguismo passa a ser um contexto comum, possibilitando que essas comunidades se integrem à maioria social, incluindo-as na sociedade e na cultura daquele lugar.

No caso do Canadá, que tem dois idiomas oficiais (o inglês e o francês), o bilinguismo não está restrito à sala de aula, sendo a escola apenas mais um contexto de aquisição das duas línguas simultaneamente, porque é possível presenciar a mesma característica nas suas ruas, cidades, restaurantes etc. De acordo com o Censo de 2011, o inglês é a língua materna de $58 \%$ dos 
canadenses. E o francês de $22 \%$ da população. Esse Censo também revelou que mais de $\mathbf{5 . 7 9 5 . 0 0 0}$ pessoas no Canadá falam os dois idiomas oficiais do país. Esses indivíduos bilíngues representam $17,5 \%$ da população. Tudo isso se deve à colonização do Canadá, que foi feita, principalmente, pelas Ilhas Britânicas e pela França.

Já no Brasil, a condição de ser bilíngue é geralmente procurada por uma minoria privilegiada, que busca uma eficiente comunicação com o mundo externo devido ao contexto social do país, que, "mesmo sendo uma nação de dimensões continentais e riquíssima em recursos naturais, (...) desponta uma triste contradição, de estar sempre entre os dez países do mundo com o PIB mais alto e, por outro lado, estar sempre entre os dez países com maiores índices de disparidade social"3. Nesse sentido, o bilinguismo está associado a uma ideia de prestígio, de status, que ajuda a manter e fortalecer a posição de determinados grupos da sociedade ${ }^{4}$. Afinal, a fluência na segunda língua representa um diferencial, e o mercado de trabalho brasileiro considera, cada vez mais, uma boa fluência no inglês um requisito básico para a maioria das oportunidades de emprego ${ }^{5}$.

É importante esclarecer que o bilinguismo compreende relações entre duas línguas em outros contextos também, como o de certas comunidades indígenas brasileiras que hoje fazem parte de uma cultura minoritária e vivem, de certa forma, dominadas e isoladas. A população indígena brasileira não é composta por um só povo, mas por muitos, cada qual com seus costumes, habilidades, tecnologias, atitudes estéticas, organização social, crenças religiosas e filosóficas peculiares. $\mathrm{E}$, segundo o Instituto Brasileiro de Geografia e Estatística (IBGE), o Censo 2010 revelou que 274 línguas indígenas são faladas no país ${ }^{6}$, sendo que a população total de índios no Brasil é de 896.917 pessoas, ou seja, a partir desses dados podemos reconhecer a multilinguagem brasileira.

0 ingresso de crianças brasileiras em escolas bilíngues não era comum até 30 anos atrás, pois estas eram frequentadas, em sua maioria, por crianças estrangeiras. Eram escolas internacionais, que atendiam a alunos nascidos no exterior que passavam a residir no Brasil e que tinham alguma língua estrangeira como sua primeira língua. Aos poucos, esse cenário foi mudando e, com a crescente valorização da habilidade e fluência numa segunda língua - especialmente por uma classe média em ascensão -, um número maior de crianças brasileiras passou a ingressar em escolas internacionais e em escolas de imersão, que começaram a ser inauguradas especialmente nas grandes cidades. Essas escolas
3. Desigualdade Social no Brasil. Disponível em: goo.gl/WZoQT9. Acesso em 20.06.2017.

4. MIRANDA, Nilva Conceição Ensino de língua inglesa no Brasil, políticas educacionais e a formação do sujeito da educação básica. Disponível em: goo.gl/ YLNbNt. Acesso em 20.06.2017.

5. Catho: A importância do inglês para a carreira. Disponível em goo.gl/TP6xPQ; Catho: A importância da língua inglesa no mercado de trabalho. Disponível em: goo.gl/vBU8NV; Jornal Hoje: Domínio de português e inglês é essencial no mercado de trabalho. Disponível em: goo.gl/ysKghG. Acesso em 20.06.2017.

6. Censo 2010: população indígena é de 896,9 mil, tem 305 etnias e fala 274 idiomas. Disponível em: goo.gl/A6jodp. Acesso em 20.06.2017. 
são atraentes principalmente pelo perfil bicultural ou multicultural da instituição, além da oportunidade de oferecer a fluência em uma segunda língua.

Em nosso país, a educação bilíngue cresce consideravelmente. Segundo matéria publicada no jornal 0 Estado de S. Paulo ${ }^{7}$, o número de escolas bilíngues no Brasil saltou de 145 em 2007, para 180 em 2009, registrando um aumento de $24 \%$ no período. Ainda em 2009, outros sete colégios bilíngues estavam abrindo as portas só em São Paulo. Não existem dados atualizados sobre o número de escolas bilíngues no Brasil, mas sabemos que somente da Maple Bear Canadian School ${ }^{8}$ há 104 unidades espalhadas por todas as regiões brasileiras ${ }^{9}$. É importante destacar que aproximadamente $80 \%$ das escolas bilíngues brasileiras estavam localizadas apenas em território paulista, conforme essa mesma matéria publicada no jornal O Estado de S.Paulo.

É fundamental reconhecermos que o conceito de bilinguismo é bastante amplo, o que faz com que escolas com os mais variados objetivos linguísticos e culturais sejam enquadradas nessa abrangente nomenclatura. Além disso, a regulamentação para o funcionamento de uma escola de educação bilíngue ainda é muito deficiente, como veremos mais à frente, facilitando divergências, por exemplo, quanto ao tempo de exposição à segunda língua.

Portanto, para que possamos situar o modelo de educação bilíngue de que este estudo irá tratar, primeiramente é necessário esclarecer alguns conceitos importantes, tais como o que é bilinguismo e quais os tipos de educação bilíngue. Esses conceitos permitirão contextualizar o trabalho. E, a partir de agora, utilizaremos a nomenclatura L1 para tratar da primeira língua, a língua adquirida ${ }^{10}$, e L2 para tratar da segunda língua, a língua aprendida ${ }^{11}$.

\section{0 que define uma escola como bilíngue?}

Um grande número de escolas da cidade de São Paulo vem se autodenominando bilíngue. Porém, é preciso entender que educação bilíngue é um termo bastante amplo, que pode se referir ao trabalho realizado em escolas com os mais variados objetivos linguísticos e culturais, como as escolas para surdos (Libras ${ }^{12}$ português) e as escolas indígenas (língua indígena-português). Portanto, é importante que fique claro que esse trabalho tratará do bilinguismo relativo aos idiomas português-inglês no contexto da educação bilíngue brasileira, sendo a cidade de São Paulo seu principal foco.
7. ESTADO, Agência. Cresce procura por escolas bilíngues no País. Jornal O Estado de S.Paulo. Disponível em: goo.gl/f9bbXe. Acesso em 20.06.2017.

8. Escola bilíngue de imersão que importa a metodología canadense por meio de franquias de escolas.

9. No site da Maple Bear Canadian School é possível visualizar esses dados na parte inferior da seguinte página. Disponível em: goo.gl/FiWHEG. Acesso em 20.06.2017.

10. Schütz (2006), define Language Acquisition como "processo de assimilação natural, intuitivo, subconsciente, fruto de interação em situações reais de convívio humano, em que o aprendiz participa como sujeito ativo". Um exemplo é o processo de assimilação da língua materna pelas crianças. Nesse sentido a criança, para se comunicar, adquire um conhecimento prático-funcional sobre a língua falada, por meio da interação com as pessoas que a cercam, e não um conhecimento teórico da sua língua materna.

11. Language Learning tem como premissa que o aluno entenda, através da língua na forma escrita, a estrutura e as regras do idioma. É através de esforços intelectuais e capacidade dedutiva-lógica que ele vai entender a língua. Portanto, podemos relacionar esse processo com a abordagem do ensino tradicional de línguas aplicado nas escolas (ensino médio, muitos cursos de línguas, etc...) (SAPUCAIA, p. 3).

12. Libras - Língua Brasileira de Sinais. 
Primeiramente, a educação bilíngue português-inglês busca se comunicar de uma maneira eficiente com o mundo globalizado atual, que se modifica em um período de tempo cada vez mais curto. Em segundo lugar, o bilinguismo permite que um indivíduo seja inserido em uma realidade de ensino onde a L2 apresenta para ele outra cultura, ampliando seu universo cultural e o modo como enxerga as coisas.

Ferguson, Houghton \& Wells (1977) citam alguns exemplos de objetivos da escola bilíngue que se encaixam na realidade paulistana:

\begin{abstract}
Propiciar a comunicação com o mundo externo; proporcionar aptidões linguísticas vendáveis, dando apoio à posição no mercado de trabalho e status; fortalecer grupos de elite e preservar sua posição na sociedade; e aprofundar a compreensão de língua e cultura.
\end{abstract}

Para finalizar, o Portal Educação Bilíngue ${ }^{13}$ caracteriza a escola bilíngue como "uma escola que ensina por meio das línguas e não apenas as línguas, sendo essa a principal diferença em relação a escolas de idiomas. Isso significa que os alunos não têm apenas aulas de inglês, francês, espanhol, Libras ou línguas indígenas, mas têm, principalmente, aulas de diversas matérias em inglês, francês, espanhol, coreano, Libras, línguas indígenas ou qualquer outra", ou seja, o idioma deixa de ser o objeto a ser estudado e passa a ser a maneira de se comunicar. É utilizando esse idioma que se aprenderão novos conteúdos; portanto, o aprendizado da L2 passa a ser transdisciplinar e prático. Mas será que as escolas bilíngues, em geral, consideram essa possibilidade e trabalham dessa forma? Será que há alguma legislação que garanta essa possibilidade? veremos isso mais adiante.

\section{Quais as diferenças entre a escola bilíngue de imersão e a internacional?}

Para o bilinguismo de imersão, a L2 precisa ser introduzida a partir da Educação Infantil e deve ser a língua mais falada e aprendida até a fase de alfabetização, ou seja, a escola bilíngue de imersão é uma escola em que a criança falante de uma língua materna, no caso o português, entra na escola e recebe sua educação ou boa parte dela em uma segunda língua, no caso o inglês.

Nessa variedade de bilinguismo, são levados em consideração a idade de ingresso da criança na escola e o período de tempo que
13. Portal Educação Bilíngue. 0 que é uma escola bilíngue? goo.gl/Pmx44z. Acesso em 20.06.2017. O Portal Educação Bilíngue no Brasil começou em março de 2008, com a intenção de divulgar informações sobre educação bilíngue de forma mais acessível. Os responsáveis por ele são grandes mestres e doutores brasileiros especialistas em bilingüismo, tais como Marcello Marcelino e Elizabete Flory, que também fazem parte das referências bibliográficas deste trabalho. 
ela estará exposta ao aprendizado da L2. Segundo Baker (1998, p. 496), é a idade em que a criança começou a ter contato com essa experiência que nomeia o tipo de imersão da qual ela faz parte:

- Imersão inicial é aquela em que a criança ingressa na escola bilíngue de imersão durante a Educação Infantil ou até os 8 anos.

- Imersão mediana é aquela em que a criança ingressa com 9 ou 10 anos.

- Imersão tardia é aquela em que a criança ingressa a partir do Ensino Fundamental II.

- Da mesma forma, quando analisamos a quantidade de tempo de exposição da criança na segunda língua, podemos dizer que também existem três tipos de imersão:

- Imersão inicial total: a criança começa exposta $100 \%$ do tempo à L2. Após três anos a exposição é reduzida para $80 \%$. E para os próximos anos, até o Ensino Fundamental I, a criança termina a imersão exposta $50 \%$ do tempo na língua materna e 50\% na L2 (BAKER, 1998, p. 498).

- Imersão inicial parcial: a criança recebe as instruções de aprendizagem $50 \%$ do tempo na língua materna e 50\% na $L 2$, ou seja, desde o início da vida escolar o indivíduo tem contato com as duas línguas, pelo mesmo período de tempo (BAKER, 1998, p. 496).

- Imersão tardia: as crianças ficam expostas à língua materna $100 \%$ do tempo desde a Educação Infantil até o Fundamental I e II. A alfabetização se dá na língua materna. Quando ingressam no Ensino Médio passam a ter contato com a L2.

- Os principais diferenciais das escolas bilíngues por imersão, em geral, são:

- Os educadores nem sempre são estrangeiros, podendo ser apenas bilíngues. Sendo assim, geralmente, a equipe é composta em sua maioria por brasileiros fluentes no inglês, carregando em suas vivências um pouco das duas culturas, colocando as crianças em contato com as culturas das línguas que estão aprendendo. 
- Na maioria das vezes segue-se o currículo brasileiro, mas com uma grande carga horária na $L 2$, nesse caso o inglês. Ou respeita-se um programa, com algumas adaptações para a realidade brasileira e voltada para a aquisição da $\mathrm{L} 2$.

- O calendário escolar é o mesmo das escolas brasileiras, seguindo os feriados e as férias adotadas no país.

De maneira geral, as escolas de educação bilíngue por imersão pretendem proporcionar às crianças uma aprendizagem significativa e contextualizada na $\mathrm{L} 2$, sem deixar de lado a cultura associada à L1, tendo como principal objetivo formar indivíduos com boa fluência em dois idiomas, pois, na maioria das vezes, existe um foco na L1 também. É importante ressaltar que as escolas internacionais também pretendem proporcionar às crianças uma aprendizagem significativa e contextualizada na $L 2$. Porém, em geral, a cultura da L1 é restringida nesse contexto, já que praticamente todos os repertórios (músicas, histórias, matérias etc.) são oferecidos em outro idioma e, portanto, estão relacionados à outra cultura, que não a da L1. Mas, independentemente do modelo de bilinguismo, é desafiador pensar em como transmitir a cultura da L1 em um contexto bilíngue.

Exemplos de escolas bilíngues por imersão presentes na cidade de São Paulo: See-Saw-Panamby Bilingual School; PlayPen; My School; Maple Bear; Tiny People Bilingual School, entre outras.

Outro modelo de educação bilíngue presente em São Paulo é a escola bilíngue internacional, que surge em diversos países com o intuito de proporcionar um currículo estável e adequado às necessidades das crianças que mudam de país, muitas vezes por motivos profissionais dos pais. Portanto, essas escolas têm como principal objetivo proporcionar uma educação seguindo uma metodologia própria do país de origem da escola, ou por meio de programas internacionais ${ }^{14}$, tentando estabelecer um padrão, tanto curricular quanto cultural, fazendo com que as crianças aprendam ambas as línguas, tendo, porém, a língua comum da escola (L2) um foco maior que a língua portuguesa (L1). Mesmo assim, o objetivo é que, ao final da vida escolar, as crianças estejam aptas a se comunicar com proficiência em ambos os idiomas. É comum que alunos de escolas internacionais cheguem à escola falando o idioma estrangeiro, sem saber falar o português, no caso do Brasil. Por consequência, o idioma estrangeiro facilita o deslocamento dessas crianças entre os países, por ser a língua comum nas escolas internacionais. Ao mesmo tempo, o idioma nativo do país em que a escola está situada vai sendo aprendido aos poucos pelas crianças vindas do exterior.
14. Ambas escolas, internacionais e de imersão, podem vir a adotar um programa pedagógico. Algumas escolas de imersão importam programas pedagógicos de outros países, como as unidades da Maple Bear, que utilizam o programa pedagógico feito por uma instituição canadense. A diferença é que, no caso da escola internacional, esse programa é reconhecido internacionalmente. Ao mesmo tempo, os dois programas, normalmente, possuem temas transdisciplinares ou unidades de investigação cujas atividades abrangem todas as áreas do conhecimento. Além disso, esses programas precisam se adaptar a qualquer realidade, principalmente os programas internacionais. No Brasil, por exemplo, os programas podem ser seguidos desde que estejam de acordo com os documentos oficiais do Ministério da Educação, tais como os Parâmetros Curriculares Nacionais (PCN, 1997). Retomaremos a questão da legislação para a educação bilíngue mais à frente. 
Até pouco tempo, não era comum o ingresso de crianças brasileiras nessas escolas. Em sua maioria, elas eram frequentadas por crianças estrangeiras. Porém, de alguns anos para cá, muitas crianças brasileiras ingressaram ${ }^{15}$ em escolas internacionais. Alguns dos motivos para o aumento dos alunos brasileiros em escolas internacionais são: uma possível atração pela fluência em uma segunda língua, a vivência em um contexto bicultural ou multicultural oferecido pela instituição e a viabilização de oportunidades no exterior, como universidades e ofertas de emprego, além do aumento do poder aquisitivo de parte da população brasileira, que já era considerada alta baixa ${ }^{16} \mathrm{e}$ passou a ser considerada alta média ${ }^{17}$, pois essas escolas cobram mensalidades ainda mais altas do que as das escolas bilíngues de imersão, que, por sua vez, oferecem um preço mais elevado que o das escolas não bilíngues.

Em linhas gerais, as principais características das escolas internacionais são:

- As escolas internacionais seguem uma metodologia ou um programa de seu país de origem ou internacional.

- Os professores dessas escolas são predominantemente estrangeiros e especialmente recrutados pela escola, passando por um processo seletivo diferenciado.

- A cultura predominante na escola é a do país de origem.

- Segue-se o calendário do país de origem, podendo acontecer de o ano letivo iniciar em agosto e terminar em julho do ano seguinte, conforme ocorre em alguns países do hemisfério norte. Porém, normalmente os feriados nacionais e municipais do local onde a escola está instalada também são seguidos.

- As escolas internacionais tiveram que incluir na grade curricular o currículo nacional brasileiro para as disciplinas de Língua Portuguesa, História e Geografia para serem reconhecidas pelo MEC. 0 que acontece na maioria das escolas internacionais, é que as aulas de Português, História e Geografia são ministradas em português, por um professor brasileiro, e em menor carga horária em relação ao currículo em inglês, que engloba a maioria das disciplinas.

- Alguns exemplos de escolas internacionais na cidade de São Paulo: Escola Graduada (Graded School), que foi a primeira, fundada em 1920; Escola Britânica (St. Paul's School),
15. Ainda não se tem pesquisas nem dados oficiais para se medir esse aumento. As informações relacionadas ao universo bilíngue, apesar de atualmente estarem em destaque, estão pouco embasadas teoricamente.

16. R\$ 17.434 - Renda média familiar, segundo o critério da Associação Brasileira de Empresas e Pesquisas (Abep), da classe alta baixa. G1 - Veja diferenças entre definições de classes sociais no Brasil. Disponível em: goo.gl// Bn4fSA. Acesso em 20.06.2017.

17. Não há uma definição de renda média familiar para essa classe social, segundo a Abep; porém, podemos dizer que ela, com certeza, deverá ser superior a R\$ 17.434,00 (Classe alta baixa). G1 - Veja diferenças entre definições de classes sociais no Brasil. Disponível em: goo.gl/Bn4fSA. Acesso em 20.06.2017. 
fundada em 1926; Escola Maria Imaculada (Chapel School), em 1947; Saint Nicholas, em 1980, entre outras.

\section{A escola bilíngue e a legislação brasileira}

0 ensino de línguas estrangeiras foi iniciado no Brasil em 1837, com a criação do Colégio Pedro II, e foi por muito tempo dedicado apenas à elite brasileira (CHAGAS, 1976, p. 105). A aprendizagem de línguas apenas ganhou destaque quando foi inserida no currículo escolar da educação básica, por meio da Lei de Diretrizes e Bases da Educação número 9.394/96, determinando a oferta de línguas estrangeiras na escola regular (BRASIL, 1996, apud PAIVA, 2003). Carneiro (2004) ressalta que tal determinação permitiu que o currículo fosse adaptado conforme as peculiaridades de cada região. Nas regiões em que há uma colonização alemã, por exemplo, foi permitido que o alemão fosse ensinado como L2.

Nas outras regiões do país, em que não há outros idiomas peculiares, o inglês ou o espanhol são as línguas estrangeiras ensinadas, devido à localização do Brasil e à abrangência dessas línguas no contexto mundial. Porém, é fundamental diferenciar o ensino de línguas estrangeiras do ensino bilíngue. A educação regular que ensina línguas estrangeiras tem como objetivo noções básicas de comunicação escrita e oral, diferentemente da educação bilíngue, que tem como objetivo a aquisição de um nível avançado de comunicação na L2.

Hoexter (2016, p. 11) aponta que "de acordo com o Parecer do Conselho Municipal de Educação (CME) de São Paulo, número $135 / 2008$, os supervisores escolares, quando analisam pedidos de autorização de funcionamento de escolas bilíngues de iniciativa privada para o segmento Educação Infantil se deparam com projetos políticos pedagógicos (PPP) e regimentos escolares com propostas de ensino bilíngue com organização variada".

A regulamentação existente para as escolas bilíngues ainda possibilita que elas atuem de formas variadas; portanto, não existe um projeto pedagógico com parâmetros específicos para essas escolas. Como consequência, isso possibilita uma ampla gama de métodos pedagógicos para a educação bilíngue, permitindo que algumas escolas promovam apenas a intensificação de um segundo idioma. Recentemente, por exemplo, algumas escolas no município de São Paulo passaram a promover o bilinguismo como uma proposta extracurricular, ou seja, como um contexto optativo no contraturno escolar. 
Uma pesquisa realizada pelo Datafolha ${ }^{18}$ com 117 colégios teve como resultado $28 \%$ deles se autointitulando bilíngues, sendo que muitos desses colégios apenas possuem uma carga horária maior na L2. De acordo com a Organização das Escolas Bilíngues do estado de São Paulo $\left(\mathrm{OEBI}{ }^{19}\right)$, para ser caracterizada como bilíngue, a escola precisa ter, na Educação Infantil, $75 \%$ da carga horária na L2; no Ensino Fundamental, 35\%; e, no ensino médio, no mínimo, $25 \%$.

O Portal Educação Bilíngue ${ }^{20}$ esclarece: "Todas as escolas brasileiras devem obedecer às determinações da Lei de Diretrizes e Bases da Educação, além de determinações do MEC e dos conselhos estaduais de educação, que definem, por exemplo, a carga horária mínima e a quantidade de dias letivos". Segundo o mesmo portal, "para dar conta de acrescentar conteúdos curriculares em uma segunda língua as escolas precisam ampliar a carga horária. 0 recomendável é que pelos menos três horas por dia sejam dedicadas ao ensino na segunda língua. Por isso, as escolas bilíngues precisam funcionar em período integral ou semi-integral, garantindo ao aluno tempo para estudo nas duas línguas".

Por exigência do MEC, o Português, a partir da Educação Infantil, deve ocupar pelo menos $60 \%$ da carga horária, e a segunda língua, no mínimo $25 \%$. 0 MEC também exige que as escolas bilíngues trabalhem no máximo $50 \%$ de cada idioma (L1 e L2), o que vai de encontro com a caracterização de escola bilíngue da OEBI, conforme vimos acima. Apesar dessas exigências, não existe no Brasil uma regulamentação específica para o ensino bilíngue, apenas para o ensino de línguas estrangeiras.

A formação adequada dos profissionais, principalmente dos que vão trabalhar em sala de aula, também é essencial para a efetivação do ensino bilíngue no Brasil, porque se o profissional não tiver domínio completo do segundo idioma pode comprometer a qualidade do ensino. É necessário que os professores das escolas bilíngues tenham especialização e fluência na segunda língua, além de conhecimento acadêmico sobre bilinguismo, pois, segundo Hoexter (2016), no cotidiano educacional verifica-se certo desconhecimento dos fundamentos do bilinguismo, suas possibilidades, limitações e alcances.

Atualmente, além da falta de padronização para a atuação das escolas bilíngues, não existe sobre elas uma supervisão sistemática e periódica por parte das Secretarias de Educação, o que dificulta o estabelecimento de um padrão de qualidade, porque não é possível
18. FOLHA. 'Mergulho' no idioma define boa escola bilíngue. Disponível em: goo.gl/774a1D. Acesso em 20.06.2017.

19. OEBI (Organização das Escolas Bilíngues do Estado de São Paulo). Disponível em: http:// www.oebi.com.br. Acesso em 20.06.2017.

20. Portal Educação Bilíngue. Legislação e escolas bilíngues no Brasil. Disponível em: goo.gl// QMcoAP. Acesso em 20.06.2017. 
identificar quais os parâmetros a serem seguidos nem levantar critérios para avaliar a escola bilíngue, consequentemente.

A regulamentação de escolas bilíngues exige adequação, revisão das práticas e reflexão sobre as estratégias de formação profissional, para que realmente responda às características de um contexto bilíngue e atenda às demandas educacionais. Portanto, o estabelecimento de padrões claros de qualidade que permitam avaliar a escola bilíngue é necessário, especialmente em um contexto no qual muitas escolas que se dizem bilíngues agem completamente diferente, descaracterizando o conceito de bilíngue. Só assim será possível garantir a educação bilíngue no contexto brasileiro.

\section{0 que significa ser bilíngue?}

Segundo o dicionário 0xford (2000, p. 117), ser bilíngue é "ser capaz de falar duas línguas igualmente bem porque as utiliza desde muito jovens". Na visão popular, ser bilíngue é o mesmo que ser capaz de falar inteiramente duas línguas diferentes. Contudo, não existe um consenso entre os teóricos acerca de uma definição simples e única sobre o que é um sujeito bilíngue. Habilidade, competência, proficiência e performance são termos usados pelos estudiosos do bilinguismo para conceituar o ser bilíngue.

Opondo-se a essa visão de bilíngue como proficiente na L2 e na L1 igualmente, encontramos Macnamara (1967, apud HARMERS e BLANC, 2006, p. 6), que propõe que uma pessoa bilíngue é aquela que possui uma competência mínima em uma das habilidades linguísticas como falar, compreender, ler e escrever em uma língua diferente da sua língua materna.

Weinreich (1953, p. 5, apud Rocca 2003), por sua vez, define bilinguismo como a capacidade prática de utilizar alternadamente duas línguas. Partindo desse pressuposto, Ferreira (2009, p. 205) afirma que o sujeito bilíngue é "aquele que alterna entre línguas, considerando as condições, os objetivos e o contexto social da alternância".

Medina (1997, p.18), por sua vez, acredita que o sujeito bilíngue é aquele que possui competência para compreender, falar e escrever na $L 2$, sem que para isso precise da $L 1$, pois é capaz de pensar na língua L2 como se fosse sua L1. Esse sujeito bilíngue possuirá a capacidade de alternar entre as línguas, por sua vontade, sem apresentar qualquer dificuldade de comunicação. Ou seja, o ser 
bilíngue para Medina consegue pensar em duas línguas diferentes sem necessidade de apoio de uma para a outra.

Por não existir um padrão que determine a proficiência em determinada língua, essa definição de bilinguismo, ou de sujeito bilíngue, é complexa. $\mathrm{E}$, pensando dessa forma, neste artigo procuro utilizar como referência a definição de Flory e Souza (2009), que acabam por definir o conceito de bilinguismo como algo "multifacetado e não consensual", sendo representado na prática escolar sob diversas metodologias de ensino. Para elas, cada indivíduo possui um tipo de bilinguismo específico:

\section{O tipo de bilinguismo desenvolvido por um sujeito relaciona-se a características individuais e contextuais, como, por exemplo, idade de aquisição das línguas, tempo de exposição a essas línguas, presença ou ausência da segunda língua no ambiente em que a criança vive. (FLORY, SOUZA, 2009, p. 24).}

Para conceituar bilinguismo, Harmers e Blanc consideram importante analisar seis dimensões: competência relativa, organização cognitiva, idade de aquisição, presença ou não de indivíduos falantes da L2 no ambiente de convivência, status das línguas envolvidas e identidade cultural (HARMERS e BLANC, 2000 apud MEGALE, 2005, p.3):

1. Competência relativa: Sob essa dimensão é possível que o bilinguismo seja balanceado e/ou dominante. Bilinguismo balanceado é aquele em que o indivíduo tem as competências para falar, compreender, ler e escrever em equilíbrio, tanto na língua materna quanto na L2. No bilinguismo dominante, a pessoa tem uma competência maior em uma das duas línguas, sendo essa, normalmente, na língua materna.

2. Organização cognitiva: Nessa dimensão devemos considerar o conceito de bilinguismo composto. 0 bilinguismo composto ocorre quando a pessoa faz uma representação mental para as duas línguas, isto é, tem uma imagem mental para a mesma palavra nas duas línguas ${ }^{21}$. Exemplo: terá uma imagem de casa tanto para a palavra na língua materna como para a L2.

3. A idade de aquisição: Dependendo da idade em que a L2 é adquirida, considera-se bilinguismo infantil, adolescente e adulto. 0 bilinguismo infantil ocorre quando a criança aprende a segunda língua até os 10/11 anos e é dividido em bilinguismo simultâneo e o bilinguismo consecutivo. No simultâneo, a criança, desde pequena, adquire a L2 ao mesmo tempo que
21. GUASTI, M.T. Language acquisition: the growth of grammar. Cambridge: The MIT Press, 2002. Capítulo 3 
aprende a língua materna. No consecutivo, a L2 é adquirida na infância, após a criança ter aprendido o básico da língua materna, mais ou menos aos 5 anos de idade. No bilinguismo adolescente, o indivíduo adquire a L2 entre os 11 e 17 anos. No bilinguismo adulto, a L2 é adquirida após os 17 anos. ${ }^{22}$

\section{Presença ou não de indivíduos falantes da $L 2$ no ambiente de convivência em que a criança está inserida e aprendendo} a L2: Nessa dimensão ocorrem dois tipos de bilinguismo: 0 endógeno e o exógeno. No bilinguismo endógeno existe a presença da L2 no ambiente social em que a criança está inserida e essa língua possui uma função social. No exógeno também existe a presença da L2 no ambiente social, porém esta não é falada com frequência. Considerando essa dimensão, é possível questionar a carga horária em inglês adotada pela escola e o contexto em que essas crianças utilizam a L2 para se comunicar, já que ele pode se dar apenas na escola. 0 contexto de aprendizagem também pode ser influenciado pelo fato de que há diferenças entre crianças que falam a L2 em casa, ou em outros ambientes, e as que não falam; afinal, nem todas as famílias que colocam seus filhos em escolas bilíngues falam a língua comum utilizada na escola.

5. Status da língua: Essa dimensão divide o bilinguismo em aditivo e subtrativo. No aditivo, as duas línguas têm a mesma importância e as duas culturas são valorizadas, pois assim não se privilegia uma só língua e uma só cultura, e a L2 é aprendida sem prejudicar o aprendizado da língua materna ${ }^{23}$. No bilinguismo subtrativo, a língua materna é desvalorizada, comprometendo o aprendizado da criança nessa língua na medida em que o aprendizado e a cultura da L2 passam a ser mais valorizados. Por exemplo: brasileiros que vão morar fora do país e, ao conviver com uma nova língua, aos poucos eliminam a língua materna de seu convívio social.

6. A identidade cultural: Relaciona-se à aculturação das crianças bilíngues (contato com as duas línguas). No bilinguismo bicultural existe uma identificação e relação positiva entre as duas línguas e culturas, isto é, há uma integração de culturas na qual a criança mantém a própria cultura e assimila a nova com facilidade. No bilinguismo monocultural a criança se identifica e é reconhecida apenas em uma cultura, normalmente em sua própria, e nega a segunda. No bilinguismo acultural a criança assimila, assume a cultura
22. MARCELINO, Marcello (2009) Bilinguismo no Brasil: significado e expectativas. Revista Intercâmbio. volume XIX, 1-22. Disponível em: goo.gl/StnxLV e, GONÇALVES (2010) 0 processamento linguístico de bilíngues e aprendizes de L2). Disponível em: goo.gl/dk6siW. Acesso em 20.06.2017.

23. Em que medida o aprendizado da L1 pode ser prejudicado pelo aprendizado da L2? Segundo Lightbown \& Spada (2006, p. 30-33), "Apesar de alguns estudos mostrarem atrasos iniciais menores em uma ou em ambas as línguas, para os bilíngues simultâneos, não há evidências de que o aprendizado de duas línguas diminua substancialmente o ritmo de desenvolvimento linguístico ou interfira no desenvolvimento cognitivo. [...] As limitações que podem ser observadas nos indivíduos bilíngues têm mais probabilidade de estarem relacionadas com as circunstâncias em que cada língua é aprendida do que com qualquer limitação na capacidade humana de se aprender mais do que uma língua. Por exemplo, se uma língua é ouvida mais frequentemente do que outra, ou é mais valorizada na comunidade, essa língua pode, eventualmente, ser utilizada melhor do que, ou preferencialmente, do que a outra.". Portanto, "se os alunos de uma segunda língua têm um conhecimento limitado da língua da escola e não têm oportunidade de continuar a aprender o conteúdo acadêmico em uma língua que já conhecem, não é de se surpreender que eles se atrasem para aprender o assunto 
e a língua da L2 e despreza tudo o que se relaciona à língua materna. E no bilinguismo descultural a criança se priva da sua cultura e da sua língua, não se adaptando nem à cultura da $L 2$, nem à sua cultura. A consequência, nesse último caso, é a dificuldade em se comunicar com competência em qualquer língua. 0 que, segundo a minha experiência, é muito raro, porque há uma fase de adaptação, de rejeição de uma das línguas, algumas vezes, mas aos poucos isso vai sendo trabalhado, tanto na escola quanto na família. Algumas vezes isso em decorrência de um choque cultural em que a criança não se identifica com a cultura brasileira porque fala outro idioma e não se identifica com a cultura do país de língua inglesa porque seu contexto é diferente; por exemplo, apresenta outro biotipo, religião e características culturais. E não tem problema a criança escolher uma cultura com a qual mais se identifica. 0 importante é ela ser exposta às diferentes culturas com respeito às particularidades de cada cultura. E as línguas sempre carregam identidades culturais; desta forma, a partir do momento em que a criança adquirir uma língua, ela também vai adquirir uma cultura.

Considerando todas essas informações, pudemos observar que não existe uma única definição do que é bilinguismo, e sim um conjunto de princípios básicos, como a interação social e individual que a criança tem por meio de ambas as línguas, o desenvolvimento das habilidades linguísticas (ler, escrever, compreender, falar) na aquisição das línguas, as funções sociais que elas representam e a interação recíproca entre as línguas e suas respectivas culturas.

São muitos os caminhos para que uma pessoa se torne bilíngue e, como se pode notar, é primordial que se observe o contexto no qual o sujeito está inserido para, assim, compreender de qual tipo de bilinguismo estamos tratando.

\section{Considerações finais}

Em nosso país, a educação bilíngue conquista cada dia mais espaço. As escolas bilíngues de imersão e internacionais vêm progressivamente atraindo mais alunos, principalmente pelo perfil bicultural ou multicultural dessa modalidade de instituição, além da oportunidade de oferecer a fluência em uma segunda língua. Essa condição de ser bilíngue é, geralmente, procurada por uma minoria privilegiada, que busca uma comunicação eficiente acadêmico que seus pares continuaram a desenvolver. Atualmente, $[\ldots]$ algumas pesquisas sugerem que o desenvolvimento contínuo da língua materna da criança realmente contribui, a longo prazo, para uma aquisição mais bem-sucedida da língua escolar, pois [..] quando as crianças são submersas' numa língua diferente durante períodos prolongados na creche ou pré-escola, o desenvolvimento da língua familiar pode ser retardado ou paralisado antes de ter se desenvolvido uma proficiência em termos de idade na nova língua. Eventualmente, eles podem parar de falar a linguagem da família completamente, e esta perda de linguagem comum pode levar a significativos problemas sociais e psicológicos, [...] o que pode ter consequências negativas para a autoestima das crianças, e as suas relações com os membros da família, que também ficarão suscetíveis a serem afetados por essa perda precoce da língua familiar. Neste caso, as crianças parecem continuar a serem capturadas entre duas línguas, pois: ainda não dominam a língua escolar e não continuaram a desenvolver a linguagem familiar. Portanto, [...] manter a linguagem familiar também permite que as crianças mantenham conexões familiares, principalmente com os avós ou parentes que não falam a nova língua. Assim, eles se beneficiam da oportunidade de continuar o desenvolvimento cognitivo e afetivo usando uma linguagem que entendem facilmente enquanto ainda estão aprendendo a segunda língua". (Tradução livre, feita pela autora do trabalho). 
com o exterior devido ao contexto social do país e do mundo. Sendo assim, o bilinguismo parece estar associado a uma ideia de prestígio, de status, que ajuda a manter e fortalecer a posição de determinados grupos da sociedade, principalmente de uma classe média em ascensão. Afinal, a fluência na segunda língua representa um diferencial, e o mercado de trabalho brasileiro considera, cada vez mais, uma boa fluência no inglês um requisito básico para a maioria das oportunidades de emprego. Porém, neste momento, o bilinguismo deve ser visto não apenas como um diferencial mas, principalmente, como uma necessidade do mundo globalizado, que requer das pessoas um maior conhecimento e integração do mundo externo ao seu cotidiano, exigindo a aquisição de novos saberes, dentre eles o domínio de outras línguas.

Ao longo deste trabalho, vimos que um grande número de escolas da cidade de São Paulo vem se autodenominando bilíngue. Porém, o estudo teórico realizado para este trabalho pode revelar o quanto o bilinguismo e a educação bilíngue são contextos cuja compreensão é bastante ampla, tanto no que diz respeito aos diferentes objetivos linguísticos e culturais do trabalho realizado nas escolas, quanto às diferentes línguas que estarão em relação nos contextos bilíngues, como no caso das escolas para surdos (Libras-português) e das escolas indígenas (língua indígenaportuguês). Nessa pesquisa, a educação sobre a qual refletimos é a educação bilíngue português-inglês.

Essa educação bilíngue oortuguês-inglês busca se comunicar de uma maneira eficiente com o mundo globalizado atual, pois o inglês é considerado a língua mundial, já que é a segunda língua da maioria das pessoas ao redor do mundo. Isso permite que o sujeito bilíngue seja inserido em uma realidade de ensino na qual a L2 apresenta para ele outra cultura, ampliando seu universo cultural e o modo como enxerga a realidade.

0 estudo teórico realizado para este trabalho possibilitou caracterizar ambas as escolas e estabelecer algumas diferenças existentes entre elas. Porém, de modo geral, os dados recolhidos ainda não permitiram estabelecer parâmetros de comparação entre a escola bilíngue de imersão e a escola internacional, bem como indicadores da qualidade do trabalho realizado em cada uma delas. As diferenças entre as escolas pesquisadas são muito grandes quanto ao número de alunos, carga horária e espaço físico. Em um próximo estudo será fundamental incluir mais escolas na pesquisa, nas quais esses dados sejam mais próximos, diminuindo as discrepâncias e criando um campo de pesquisa mais justo do qual se parta para o que se quer saber. 
Outro aspecto importante diz respeito à regulamentação existente para as escolas bilíngues, que ainda possibilita que elas atuem de formas variadas, pois não existe um projeto pedagógico com parâmetros específicos para essas escolas, possibilitando uma ampla gama de métodos pedagógicos e permitindo que algumas instituições promovam apenas a intensificação de um segundo idioma.

A formação adequada dos profissionais, principalmente dos que vão trabalhar em sala de aula, também é essencial para a efetivação do ensino bilíngue no Brasil, porque, se o profissional não tiver domínio completo do segundo idioma, ele pode comprometer a qualidade do ensino. 0 conhecimento acadêmico sobre bilinguismo também deve fazer parte dessa formação dos profissionais, já que no cotidiano educacional verifica-se certo desconhecimento dos fundamentos do bilinguismo, suas possibilidades, limitações e alcances. Imergir em diferentes conteúdos ou o fato de haver uma vasta biblioteca não garante o bilinguismo, cujo desenvolvimento precisa ser mediado por professores que, por sua vez, devem possuir determinados saberes e competências específicas que os habilitem a atuar no contexto bilíngue, promovendo o bilinguismo. Assim, novas questões se apresentam e ficam em aberto: será que os gestores acreditam que o fato de estarem expostos a um ambiente em que a língua predominante é o inglês seja, se não o mais importante, um fator poderoso no desenvolvimento do bilinguismo das crianças?

Conjuntamente à falta de regulamentação e formação adequada de profissionais, não existe uma supervisão sistemática e periódica das escolas bilíngues de imersão e internacionais, o que dificulta o estabelecimento de um padrão de qualidade para elas, porque não é possível identificar quais os parâmetros a serem seguidos e, consequentemente, os critérios para avaliar a escola bilíngue.

0 estabelecimento de indicadores comuns para a avaliação das escolas bilíngues é necessário, especialmente numa realidade em que muitas escolas que se dizem bilíngues atuam de forma completamente diferente, descaracterizando os contextos que - conforme o estudo teórico nos apontou - poderiam ser considerados como bilíngues. Só assim será possível garantir a educação bilíngue no cenário brasileiro.

0 estudo teórico realizado, bem como a caracterização das escolas, deixa em aberto muitas questões, que emergem, principalmente, pela falta de um padrão das escolas bilíngues, por carência de embasamento teórico e, também, por causa do sigilo exigido pelas escolas em relação às metodologias empregadas. 
Algumas considerações merecem mais investigação, tais como: qual o lugar da cultura brasileira na escola bilíngue localizada no Brasil? Como se dá a alfabetização bilíngue nas escolas de imersão e internacional? Como é realizado o período de adaptação em uma escola bilíngue? Muitas delas só poderão ser respondidas se incluirmos entre os sujeitos pesquisados, em um estudo posterior, professoras/es, famílias, crianças (alunas/os) e funcionárias/os.

Este trabalho pode iluminar o quanto os contextos bilíngues necessitam de mais embasamento acadêmico. 0 aprofundamento do estudo sobre o bilinguismo, as escolas bilíngues e seus currículos pode ajudar a ampliar seu reconhecimento e importância na sociedade e, principalmente, na educação atual. Além disso, a educação bilíngue precisa deixar de estar associada a privilégio de classes econômicas mais abastadas e status, para se tornar um contexto educativo real e acessível a todos; afinal, o bilinguismo é uma necessidade educativa da contemporaneidade. É intenção da autora prosseguir em sua pesquisa sobre a educação bilíngue, focando nas questões que não foram respondidas neste trabalho, ampliando o número de escolas estudadas e incluindo entre os sujeitos pesquisados a família, os alunos e funcionários e agentes das escolas de educação bilíngue.

\section{REFERÊNCIAS}

BAKER, C. Foundations of bilingual education and bilingualism. Great Britain: Multilingual Matters, 1996.

BAKER, C.; PRYS JONE, S. Encyclopedia of bilingualism and bilingual education, Clevedon, UK: Multilingual Matters Ltda, 1998. Subcapítulo "Immersion Bilingual Education".

BOWERN, C.. Where did English come from? TED-Ed - 2015. Disponível em: goo.gl/AzxAUq. Acesso em 20.06.2017.

BRASIL. Lei de Diretrizes e Bases da Educação: Lei 9.394/96. Brasília, 1996.

CANADA. Census Recensement, 2011. Disponível em: goo.gl/ L8trtH. Acesso em 20.06.2017.

CARNEIRO, M.A. LDB fácil: leitura crítico-compreensiva artigo a artigo. Petrópolis: Vozes, 2004. 
CHAGAS, R.V.C. Didática especial de línguas modernas. São Paulo: Companhia Editora Nacional, 1976.

CRYSTAL, D. English as a global language. Cambridge: 2002. Disponível em: goo.gl/XPtNX6. Acesso em 20.06.2017.

DICIONÁRIO Oxford Escolar - Para Estudantes Brasileiros de Inglês. Oxford University Press. Oxford. 2000.

FERGUSON, C.A; HOUGHTON, C. \& WELLS, M.H (1977). Bilingual education: An international perspective. In SPOLSKY, B. \& COOPER, R. (eds) Frontiers of Bilingual Education. Rowley, MA: Newbury House

FERREIRA, E.D. O ensino de língua estrangeira na educação de jovens e adultos de Florianópolis: bilinguismo, pesquisa e intercompreensão. Rev. Bras. Linguist. Apl. Belo Horizonte, v. 9, n. 1, pp. 201-223, 2009.

FLORY, E.; SOUZA, M. Bilinguismo: diferentes definições, diversas implicações. Revista Intercâmbio, São Paulo: LAEL/ PUC-SP. ISSN 1806-275x, 2009.

FOLHA. 'Mergulho' no idioma define boa escola bilíngue. Disponível em: goo.gl/m7h6Zf. Acesso em 20.06.2017.

GONÇALVES, A.A. O processamento linguístico de bilíngues e aprendizes de L2. Revista Prolíngua, v. 5, n. 1 - ISSN 19839979, 2010 Disponível em: goo.gl/6M42NB. Acesso em 20.06.2017.

GUASTI, M. T. Language acquisition: the growth of grammar. Cambridge: The MIT Press, 2002.

HARMERS, J. e BLANC, M. Bilinguality and bilingualism, Cambridge: Cambridge University Press, 2000.

HOEXTER, F. Q. O que pensam os gestores sobre a regulamentarização e funcionamento de uma escola de Educação Infantil bilíngue. São Paulo: Instituto Vera Cruz, 2016.

LEWIS, E.G. Bilingualism and bilingual education: the ancient world to the Renaissance. In: FISHMAN, J., Bilingual Education. Rowley, Massachusetts: Newbury House, 1977)

MACKEY, W.F. (1978). The importation of bilingual education models. Georgetown University Round Table on Languages and Linguistics, 1-18. 
MACNAMARA, J. The Bilingual's Linguistic Performance - A Psychological Overview. McGill University. Journal of Social Issues. Volume XXIII, Number 2, 1967.

MARCELINO, Marcello (2009) Bilinguismo no Brasil: significado e expectativas. Revista Intercâmbio. volume XIX, 1-22. Disponível em: goo.gl/StnxLV . Acesso em 20.06.2017.

MEDINA, J.L. Lenguas en contacto. Madrid: Arco Libro, 1997. (Cuadernos de lengua española).

MEGALE, A.H. Bilinguismo e educação bilíngue: discutindo conceitos. Revista virtual de Estudos de Linguagem - ReVEL, Ano 3, n. 5, 2005. Disponível em: goo.gl/Jixypn. Acesso em 20.06.2017.

OEBI (Organização das Escolas Bilíngues do Estado de São Paulo) <http://www.oebi.com.br>. Acesso em 20.06.2017.

PAIVA, V.L.M.O. A LDB e a legislação vigente sobre o ensino e a formação de professor de língua inglesa. In: STEVENS, C.M., e CUNHA, M. Caminhos e Colheitas: ensino e pesquisa na área de inglês no Brasil. Brasília: UnB, 2003.

Portal Educação Bilíngue. Legislação e escolas bilíngues no Brasil. goo.gl/MwpTko. Acesso em 20.06.2017.

Educação Bilíngue no Brasil. O que é uma escola bilíngue? Disponível em: goo.gl/TW89PM. Acesso em 20.06.2017.

ROCCA, P.D.A. Bilingualism and speech: evidences from a study on VOT of english and portuguese voiceless plosives. Delta, 2003.

SÃO PAULO. Conselho Municipal de Educação. Parecer CME no 135/2008. Funcionamento de Escolas de Educação Infantil bilíngue. Disponível em: goo.gl/NXyox4. Acesso em 20.06.2017.

SAPUCAIA, M.K.L. Aquisição e Aprendizado: dois processos no ensino de uma segunda Língua. Centro de Comunicação e Letras - Universidade Presbiteriana Mackenzie. Disponível em: goo.gl/3ifj3p. Acesso em 20.06.2017.

SCHÜTZ, R. "Assimilação natural x ensino formal". English made in Brasil. goo.gl/mL64d9. Acesso em 20.06.2017. 
WEI, L. The bilingual reader - dimensions of bilingualism, Routledge, 2000 (Capítulo Introdutório).

WEINREICH, U. Languages in contact: findings and problems.

The Hague: Mouton, 1953.

Recebido em: 01/02/2017

Revisto em: 25/05/2017

Aceito em: 28/05/2107 